\title{
Evaluation of the Nanostructure of Pectin, Hemicellulose and Cellulose in the Cell Walls of Pears of Different Texture and Firmness
}

\author{
A. Zdunek • A. Koziol • P. M. Pieczywek • J. Cybulska
}

Received: 10 April 2014 / Accepted: 24 June 2014 / Published online: 8 July 2014

(C) The Author(s) 2014. This article is published with open access at Springerlink.com

\begin{abstract}
The nanostructure of polysaccharides is supposed to determine properties such as stiffness or diffusivity of cell walls and their functionality for various tailored properties of food. However, at present, a relation of these nano-properties with sensory texture and firmness remains to some degree unknown. In this work, water (WSP), calcium chelator (CSP) and sodium carbonate (DASP) soluble pectins, hemicellulose and cellulose, extracted from cell walls of two pear cultivars 'Xenia' and 'Conference' at their harvest times, were studied. An atomic force microscope and image analysis were used to evaluate diameter and branching of the molecules. Sensory texture of 'Xenia' was considered as better and its firmness $(87 \mathrm{~N})$ was higher than 'Conference' $(76 \mathrm{~N})$. WSP molecules were present as short molecules with a height of about $0.5 \mathrm{~nm}$ for both cultivars. A chain-like and branched CSP fraction had diameter of about $0.3-0.4 \mathrm{~nm}$ for both cultivars with a pronounced contribution of molecules with diameter of about $1 \mathrm{~nm}$ for 'Xenia', which had also higher branching index. DASP revealed similar regular structures for both cultivars however the network was much denser for 'Xenia'. A rod-like hemicellulose molecules had length of about 20-400 nm and diameter of $1 \mathrm{~nm}$ for 'Xenia' and 1-4 nm for 'Conference'. Cellulose diameter for both cultivars was about $23 \mathrm{~nm}$. This study showed that less degraded, thicker and more branched pectin molecules were associated with higher firmness and more favourable texture. Hemicellulose provided a positive contribution to texture when they were thinner and more flexible.
\end{abstract}

Keywords AFM · Pectin · Hemicellulose · Cellulose · Firmness $\cdot$ Fexture

\footnotetext{
A. Zdunek $(\varangle) \cdot$ A. Kozioł $\cdot$ P. M. Pieczywek $\cdot$ J. Cybulska Institute of Agrophysics, Polish Academy of Sciences, Doswiadczalna 4, 20-290 Lublin, Poland

e-mail: a.zdunek@ipan.lublin.pl
}

\section{Introduction}

The molecular structure of polysaccharides and their assembly are supposed to determine properties such as the stiffness (Geitmann 2010; Gibson 2012) and diffusivity (Fanta et al. 2012) of cell walls, and the functionality of these biopolymers for various tailored properties of food (Willats et al. 2006) and non-food products (Eichhorn et al. 2010). Sensory texture and firmness of fruits, which are macroscopic properties, are important for growers, the food industry and consumers, since they are one of the quality attributes used for product gradation. Texture, as a multi-parameter property, is described by such attributes as crispness, hardness, and juiciness (Bourne 2002), which correlate with instrumental parameters such as firmness and acoustic descriptors (Zdunek et al. 2010a, 2010b, 2011a, 2011b). These descriptors, both sensory and instrumental, relate directly to mechanical properties and have their origin in the structure of tissue (Aguilera 2005). The mechanics of plants is governed by turgor (Zdunek and Bednarczyk 2006), cell size (Zdunek and Umeda 2005; Cybulska et al. 2012) and cell wall properties, including middle lamella (Niklas 1992; Li et al. 2013). Deformation causes an increase in intracellular pressure and tension of cell walls. Depending on the relative strength of cell walls and sheer strength in the middle lamella, tissue may be disrupted throughout cell walls or in-between cells (Waldron et al. 1997). The former mode generates acoustic signals and causes a release of juice, which is responsible for crispness and juiciness. The second mode is responsible for mealiness. The mechanical properties of cell walls are determined by composition, structure and an assembly of polysaccharides (Jarvis 2011). Cellulose, hemicellulose and pectins are the basic building blocks of cell walls (Brummell and Harpster 2001). It is agreed that in the pant cell walls, cellulose macrofibrils are interlinked with hemicellulose fibrils via hydrogen bonds, whereas pectins form an amorphous matrix 
(Geitmann 2010). To date, a few studies on individual polysaccharides have suggested that the molecular structure, i.e., diameter, length and branching of polysaccharides, may be important for the texture of fruits (Chen et al. 2009; Liu et al. 2009; Yang et al. 2005; Zhang et al. 2010; Cybulska et al. 2013). However, there is lack of comprehensive studies on the role of the structure of each polysaccharide, i.e., pectins, hemicellulose and cellulose together for texture of fruits. Knowledge on the structure of these polysaccharides in cell walls is also indispensable for their utilization as a natural component for various food and non-food products.

The pectin family consists of three pectic polymers: homogalacturonan (HG), rhamnogalacturonan I (RG-I) and rhamnogalacturonan II (RG-II). The main component of pectin is D-galacturonic acid (GalA) joined in chains by $\alpha-(1 \rightarrow 4)$ glycosidic linkages. In $\mathrm{HG}$, around 100 monomers of GalA make up a 'smooth region' of pectin (Ridley et al. 2001). The HG component can be methyl-esterified, which has great value to many functional properties of pectin, e.g., gelation, binding capacity and rheological behaviour (Willats et al. 2006). RG-I, also called the 'hairy' region, is composed of repeating units of GalA in the backbone interrupted by $\alpha-1 \rightarrow$ 2-linked 1-rhamnose (Rha). The side chains that create the 'hairy' part of RG-I are arabians, galactans and arabinogalactans linked to rhamnose residue. There are two major structural models for linking HG with RG-I. In both models, HG is covalently linked to RG-I (Coenen et al. 2007). In the former, HG is interspersed with RG-I, while in the latter, HG is the side chains of the RG-I backbone (Round et al. 2010; Morris et al. 2011). RG-II is a highly branched pectic domain, which contains the HG backbone. The HG backbone is substituted with heteropolymeric side chains containing at least ten different sugars. In addition, RG-II units can be crosslinked by borate diesters, which play a significant role in the cell wall structure (Mohnen 2008).

Hemicelluloses include xyloglucans (XG), xylans, glucomannans and galactoglucomannans. In fruits, the most abundant hemicellulose is XG. In the backbone of $\mathrm{XG}$, three out of four glucose residues are substituted with xylose (Burton et al. 2010). Additional residues like galactose and fucose may be attached to xylose, depending on the origin of XG. XG has a cellulose-like $\beta$-glucan backbone, however, the glucose units form significantly shorter fibrils (about 500-3000 glucose monomers) with a ribbon-like conformation. The conformation may partially resemble a flat ribbon, which is thought to be able to hydrogen-bond to the similar $\beta$-glucan chains of cellulose on the surface of the microfibril (Albersheim et al. 2011). Moreover, some of XG molecules may penetrate and disrupt the microcrystalline parts of cellulose molecules (Pauly et al. 1999).

Cellulose is composed of $(1-4) \beta$-linked D-glucose chains, assembled together by hydrogen bonds into long microfibrils
(7,000-15,000 glucose monomer units) of about 3-4 nm diameter (Gibson 2012). The microfibrils have both crystalline and noncrystalline regions. The cellulose microfibrils themselves are aligned and bound together into macrofibrils by a matrix of hemicellulose or pectin. For apples, cellulose diameter was found in the range 20-60 nm (Cybulska et al. 2013). Gibson (2012) reviewed that from X-ray diffraction measurements, Young's modulus of cellulose was estimated to be in the range 120-170 GPa, which was confirmed by atomic force microscope (AFM) (Iwamoto et al. 2009). In cell walls, cellulose is arranged in parallel in lamellas (Geitmann 2010) and crosslinked with hemicellulose (McCann et al. 1990).

Visualization of cell wall polysaccharides with nanometre resolution is possible using an AFM (Kirby 2011; Kirby et al. 1996; Cybulska et al. 2010a, 2010b, 2011). Although cell wall assembly in conditions close to natural could be observed, recognition of individual polysaccharides and structural characterization from such a sample was impossible, the exception being cellulose macrofibrils (Cybulska et al. 2013). Therefore, to study the structure of individual polysaccharides with AFM, the molecules were extracted sequentially and adsorbed on mica (Kirby et al. 1995a, 1995b, 2008; Liu et al. 2009; Yang et al. 2005; Zhang et al. 2010, 2012; Pose et al. 2012). The literature on a relationship between the nanostructure of polysaccharides in cell walls of fruits and macroscopic texture and firmness is extremely scarce. Recently, Yang et al. (2009) showed differences in the length of sodium carbonate extracted pectin molecules of soft and crispy peach cultivars, whereas water and chelator soluble pectins (CSP) did not differ much. Chen et al. (2009) found that hemicellulose molecules of crisp Chinese cherry cultivars were thicker than soft ones. Cybulska et al. (2013) showed that apples with thicker cellulose microfibrils were more crispy and had better texture. Moreover, several studies were devoted to finding a relationship between the molecular structure of pectins and the firmness of fruits during storage. Zhang et al. (2010) found that the width of sodium carbonate extracted pectins showed the highest correlation with the firmness of peaches and that two crisp cultivars used in that study did not differ. Xin et al. (2010) found that the width of CSP from tomato relates to firmness loss during ripening. For apricot, Liu et al. (2009) showed that during storage, firmness did not change with the contents of CSP but was consistent with the morphology changes of CSP; the branching structures of CSP decreased, while the frequencies of chains with small width $(<35 \mathrm{~nm})$ and the lengths $(<500 \mathrm{~nm})$ of CSP chains increased. These results suggest that using AFM, it is possible to quantitatively characterize all polysaccharides and in this way understand inter-cultivar differences in the texture of fruits from the perspective of cell wall architecture. 
In this paper, the nanostructure of pectin, hemicellulose and cellulose from the cell walls of pear fruit were studied for the first time in one experiment. This approach was aimed at discovering a relationship between the nanostructure and macroscopic texture and firmness of pears of distinct texture. Sensory texture, firmness with acoustic emission (AE) and complementary biochemical analyses were compared with the structure of cell walls' polysaccharides, which were extracted sequentially (water-, chelator- and diluted alkali-soluble pectins, hemicellulose and cellulose). Polysaccharides were characterized quantitatively with atomic force microscopy and then analysed with new image analysis protocols to obtain a diameter distribution along molecules. Moreover, where appropriate, branching of molecules was characterized. This study provides new quantitative data on the structure of various polysaccharides, which are important for the mechanics of cell walls in fruits and may also determine other functions and utilization in food technology.

\section{Materials and Methods}

\section{Pear Fruit}

Pear (Pyrus communis L.) fruit of two cultivars 'Conference' and 'Xenia' (from the same orchard) were used in this study. Pear fruit were manually harvested in optimum harvest time as determined by grower. A batch of each cultivar consisted of 40 fruits of similar size and blushing without visible symptoms of disease or bruising. A firmness test with $\mathrm{AE}$ and sensory analysis was performed on the day of harvesting. Then, pulp from pear fruit was deeply frozen for further sample preparation for biochemical and microscopic studies. This study was performed on parenchyma tissue without the skin.

\section{Galacturonic Acid and Calcium Content}

Galacturonic acid (GalA) content in pectic fractions and calcium content were determined with a $\mathrm{San}^{++}$Continuous Flow Analyzer (Skalar, Breda, The Netherlands). GalA was determined according to the colorimetric method by Blumenkrantz and Asboe-Hansen (1973). The sample was completely decomposed in $96 \%$ sulphuric acid $\left(\mathrm{H}_{2} \mathrm{SO}_{4}\right)$ with di-sodium tetra borate $\mathrm{Na}_{2} \mathrm{~B}_{4} \mathrm{O}_{7} \cdot 10 \mathrm{H}_{2} \mathrm{O}$. Then, the products were transformed to furfuryl derivatives. The derivatives reacted with the 3-phenyl phenol to form a coloured dye, which was measured at $530 \mathrm{~nm}$. Mono-GalA solutions $(10-100 \mu \mathrm{g} / \mathrm{ml})$ were used as standards. For calcium content measurement, the sample was mixed with an acetic 8-hydroxyquinoline solution to complex magnesium. Calcium was complexed with cresol phthalein complexone in an alkaline medium; this complex was measured at $580 \mathrm{~nm}$. Calcium acetate monohydrate solutions (20-100 ppm Ca) were used as standards.

\section{Enzymatic Activity}

Enzymatic activity of pectinases was determined according to the method described by Wei et al. (2010), with some modifications. Briefly, enzymes from the cell wall were extracted from frozen pulp. Powdered flesh at $3 \mathrm{~g}$ was stirred into $6 \mathrm{ml}$ of cold $12 \%$ polyethylene glycol containing $0.2 \%$ sodium bisulphite and was centrifuged for $10 \mathrm{~min}$ at $6,000 \times \mathrm{g}$. The pellet was washed with $0.2 \%$ sodium bisulfite at $4{ }^{\circ} \mathrm{C}$. Next, the pellet was extracted with $6 \mathrm{ml}$ of cold extraction buffer containing $1 \mathrm{M}$ sodium acetate (pH 5.2), $1 \mathrm{M} \mathrm{NaCl}, 2 \%(\mathrm{v} / \mathrm{v})$ mercaptoethanol and $5 \%(\mathrm{w} / \mathrm{v})$ polyvinylpyrrolidone (PVP), at $4{ }^{\circ} \mathrm{C}$ for $1 \mathrm{~h}$. The homogenate was centrifuged for $10 \mathrm{~min}$ at $6,000 \times g$, and the supernatant was used to assay for enzyme activity.

Polygalacturonase (PG) activity was determined in the following way: enzyme extract $(0.2 \mathrm{ml})$ was mixed with $0.8 \mathrm{ml}$ of $0.5 \%$ polygalacturonic acid in a $50 \mathrm{mM}$ sodium acetate buffer ( $\mathrm{pH}$ 5.2) and incubated at $37^{\circ} \mathrm{C}$ for $2 \mathrm{~h}$. Next, $2 \mathrm{ml}$ of borate buffer $(0.1 \mathrm{M}, \mathrm{pH} 9.0)$ and $0.3 \mathrm{ml}$ of cyanoacetamide were added to the reaction mixture. After inactivation of the enzymes by boiling for $10 \mathrm{~min}$ and then cooling, absorbance was read at $320 \mathrm{~nm}$. GalA was used as a standard. One unit of activity was defined as $1 \mu \mathrm{g}$ of GalA released from $\mu \mathrm{g}^{-1}$ fresh mass (FM) $\mathrm{min}^{-1}$. In order to determine the activity of pectin methylesterase (PME), $1 \mathrm{ml}$ of crude extract was mixed with $4 \mathrm{ml}$ of $1 \%(\mathrm{w} / \mathrm{v})$ citrus pectin and titrated with $0.01 \mathrm{M} \mathrm{NaOH}$ to maintain $\mathrm{pH} 7.4$ while incubating at $37^{\circ} \mathrm{C}$ for $1 \mathrm{~h}$. One unit of activity was calculated as $1 \mathrm{mmol} \mathrm{NaOH}$ consumed $\mathrm{g}^{-1} \mathrm{FM} 10 \mathrm{~min}^{-1}$.

\section{Sensory Analysis}

Sensory analysis was performed by an expert panel consisting of ten persons trained to evaluate the texture, taste and colour properties of pear fruit using the generic descriptive method. The panellists took part in an additional training session right before the experiment, where definitions of fruit texture attributes were discussed and clarified. The following texture attributes were determined by the panellists: crispness, hardness, juiciness, mealiness and overall texture according to definitions described by Zdunek et al. (2010a). Ten pear fruit of each cultivar were used for sensory evaluation. Each person tested two samples, i.e., two quarters of fruit. Each piece was assigned a three-digit code, and the samples were presented in random order. The panellists determined the perceived intensity of texture attributes using a linear, unstructured scale, which was converted into a scale of $0-10$ points.

Firmness and Acoustic Emission

Firmness was measured on pears without skin during the puncture test performed with a universal testing machine 
(Lloyd LRX, Lloyd Instruments Ltd., Hampshire, UK). A probe with a diameter of $11.1 \mathrm{~mm}$ and a radius curvature of $8.76 \mathrm{~mm}$ was used. Crosshead speed was $20 \mathrm{~mm} / \mathrm{min}$. Firmness was defined as the maximum force of penetration within a range of up to $8 \mathrm{~mm}$. AE was measured by the system and method described in detail by Zdunek et al. (2010b). AE signal was measured using a $4381 \mathrm{~V}$ (Bruel \& Kjear, Narum, Denmark) sensor of sensitivity within a range $1-16 \mathrm{kHz}$ placed in the upper head of the Lloyd LRX. AE signal was transformed from analogue to digital one $(44 \mathrm{kHz})$, and the grouped peaks were stored as AE events. A summary of events in the puncture test was defined as the total AE events.

\section{Extraction of Cell Wall Polysaccharides}

Cell wall material was isolated from the parenchyma tissue as alcohol insoluble residue (AIR). Then, $20 \mathrm{~g}$ of pulp was boiled in $70 \mathrm{ml}$ of $70 \%$ ethanol for $20 \mathrm{~min}$. The sample was chilled, filtered and mixed with $30 \mathrm{ml}$ cold $70 \%$ ethanol. After filtration and a negative result for phenol, sulphuric acid was used to test for the presence of sugar (Dubois et al. 1956); the sample was washed twice with $10 \mathrm{ml}$ of $96 \%$ ethanol and $50 \mathrm{ml}$ acetone, and dried at $40{ }^{\circ} \mathrm{C}$.

Sequential extraction according to the method proposed by Redgwell et al. (1988), with some modifications, was used. AIR was stirred in deionized water for $6 \mathrm{~h}$ at $20^{\circ} \mathrm{C}$ and then centrifuged. Supernatant was collected as a water-soluble pectins (WSP) fraction, whereas the residue was mixed with $0.1 \mathrm{M}$ cyclohexane-trans-1.2-diamine tetra-acetate (CDTA) (pH 6.5) and stirred at $25^{\circ} \mathrm{C}$ for $2 \mathrm{~h}$, and $6 \mathrm{~h}$ after the previous step. The supernatant was separated as a CSP fraction and the residue was diluted in $0.05 \mathrm{M}$ sodium carbonate $\left(\mathrm{Na}_{2} \mathrm{CO}_{3}\right)$, with the addition of $20 \mathrm{mM}$ sodium borohydride $\left(\mathrm{NaBH}_{4}\right)$ and stirred for approx. $20 \mathrm{~h}$ at $1{ }^{\circ} \mathrm{C}$; thereafter, it was filtered and again stirred for $2 \mathrm{~h}$ at $20^{\circ} \mathrm{C}$. The diluted alkali soluble pectins (DASP) fraction was collected after centrifugation as a supernatant. The residue was then stirred with $1 \mathrm{M} \mathrm{KOH}$ with the addition of $20 \mathrm{mM} \mathrm{NaBH}_{4}$ for $18 \mathrm{~h}$ at $20^{\circ} \mathrm{C}$; thereafter, it was filtered and supernatant was collected as a hemicellulose (1 M $\mathrm{KOH})$ fraction. The residue was purified by stirring it for $2 \mathrm{~h}$ with $4 \mathrm{M} \mathrm{KOH}$ containing $20 \mathrm{mM} \mathrm{NaBH}_{4}$. After filtration, samples were stirred three times with $0.1 \mathrm{M} \mathrm{HCl}$ at $85^{\circ} \mathrm{C}$ for $30 \mathrm{~min}$ and then three times with $1 \mathrm{M} \mathrm{NaOH}$ at $85^{\circ} \mathrm{C}$, and finally rinsed with hot deionized water in order to obtain cellulose fraction.

\section{Atomic Force Microscope}

A water solution of $3 \mu \mathrm{l}$ containing the studied fractions in a concentration of approximately $10 \mu \mathrm{m} / \mathrm{ml}$ was dropped onto freshly cleaved mica. Then, the specimens were vacuum-dried at $30{ }^{\circ} \mathrm{C}$ for $2 \mathrm{~h}$ and kept in a desiccator prior to AFM observations. Bioscope Catalyst II, equipped with a
Nanoscope V controller (all from Bruker, Billerica, MA, USA) was used for imaging in the PeakForce Tapping ${ }^{\text {TM }}$ mode. A silicon nitride cantilever ScanAsyst-Air (Bruker) with a nominal spring constant of $0.4 \mathrm{~N} / \mathrm{m}$ was used for scanning. The experiment was performed in air at room temperature of about $20-22{ }^{\circ} \mathrm{C}$ and a relative humidity of 26 $30 \%$. For each sample, a minimum of five images were collected. Various scanning sizes were used depending on fraction; however, scanning resolution was better than $512 \times$ 512 lines.

\section{AFM Image Analysis}

AFM height images were subjected to a plane correction performed in SPIP 6.0.14 software (Image Metrology, Hørsholm Denmark) and consisted of polynomial fit of the first order, a line-wise correction to subtract a fitted polynomial function from each individual scan line with a polynomial degree of the third order and correction of the Z-offset using the method of bearing height to zero. All images were also smoothed with a Gaussian filter $(3 \times 3)$.

For WSP fraction, which was aggregated-like, a simple image analysis protocol based on the threshold method was developed in the SPIP software. The minima threshold was set at $0.2 \mathrm{~nm}$; then, detected objects were filtered, the criteria for the maximum area being $0.005 \mu \mathrm{m}^{2}$ and the minimum diameter $16 \mathrm{~nm}$. These filters were found to subjectively discriminate particles of reasonable size from noise and from enormous objects that had been unambiguously artificially generated. In this fraction, two parameters were used for object characterization: the maximum height and diameter of the circle of the best fit to the object.

For CSP, DASP and $1 \mathrm{M} \mathrm{KOH}$ fractions, which revealed chain-like structures, an automatic image analysis protocol was developed in Matlab (MathWorks, Natick, MA, USA) in order to apply the same criteria to each image. The approach was that the height of molecules reflected the diameter of cross-section. Similarly, as in the WSP fraction, the minima threshold was set at $0.2 \mathrm{~nm}$ to segment molecules from the background. Then, a skeleton of segmented objects was determined and used as a mask for the original image in order to mark pixels where the heights along the molecules had been collected (graphical explanation shown in Fig. 1). The skeletonized images were also used to evaluate the length of molecules and number of branching points. Branching point was determined by an algorithm detecting points where at least three pixels from $3 \times 3$ neighbourhoods of the centre pixel belonged to the skeleton. The ratio of the number of branching points to the total length of molecules detected for a fraction was defined as the branching index.

Since cellulose is tangled within cell walls, extraction of individual fibrils was ineffective. Therefore, the diameter of these objects was evaluated manually from the AFM error 
images of cell walls as a mean value from more than one thousand randomly chosen fibrils.

\section{Results and Discussion}

Nanostructure of Polysaccharides in Pear Cell Walls

Figure $2 \mathrm{a}$ and $\mathrm{b}$ presents representative AFM height images of water-soluble fractions of pectins (WSP) on mica for 'Conference' and 'Xenia', respectively. Existence of small polymers is characteristic for this fraction. Figure $2 c$ shows a histogram of the maximum height of the polymers, whereas Fig. $2 \mathrm{~d}$ shows their lateral diameter distribution. The height and lateral diameter of polymers for both cultivars appear to be similar. The majority of molecules had a height of about $0.5 \mathrm{~nm}$ and a diameter of $30 \mathrm{~nm}$. However, histograms showed small differences within a contribution of polymers, with a height of about $0.7-1.0 \mathrm{~nm}$, which for the 'Xenia' cultivar was greater at the expense of molecules at a height of about $0.5 \mathrm{~nm}$ (Fig. 2c).

Figure $3 \mathrm{a}$ and $\mathrm{b}$ illustrates representative AFM height images of CSP on mica for 'Conference' and 'Xenia', respectively. A chain-like structure is characteristic for these molecules. Moreover, they are significantly branched, with plenty of short and thin side chains attached to the main stem, which was thicker and longer than the field of view. In previous studies on CSP fraction extracted from other fruits, much shorter and less branched molecules have been observed. In this experiment, both pear cultivars revealed the same qualitative features; however, two important quantitative differences were found between them, which are presented in Fig. $3 \mathrm{c}$ and Table 1. Since length measurements were impossible for this fraction, Fig. 3c presents only the distribution of the height of molecules, which represents the diameter of their cross-section. The distributions of the 'Xenia' cultivar are clearly shifted to the right, with a hump at about $1 \mathrm{~nm}$. This means that, despite the majority of molecules having diameters of about $0.3-0.4 \mathrm{~nm}$ in both cases, CSP molecules in the 'Xenia' cultivar also consisted of much thicker molecules. Table 1 illustrates the branching index, which was 5.6 and 6.2 for 'Conference' and 'Xenia', respectively.

Figure $4 \mathrm{a}$ and $\mathrm{b}$ presents examples of AFM height images for DASP from 'Conference' and 'Xenia' absorbed on mica, respectively. Molecules of DASP look very linear and form a 2D network on mica. The network for the 'Xenia' cultivar was much denser (Fig. 4b); therefore, in this case, it was not possible to segment AFM images in order to recognize unambiguously the molecules from the background. As a result, quantitative data could be obtained only for the 'Conference' cultivar (Fig. $4 \mathrm{c}$ and Table 1). The majority of molecules had a diameter about $0.5 \mathrm{~nm}$. The self-assembly in the network caused greater branching index, which was 8.2 for 'Conference', than it was noted for CSP fraction. It was not possible to measure this parameter for 'Xenia', as per the above mentioned reasons. However, the presented AFM image in Fig. $4 \mathrm{~b}$ for this cultivar shows that the molecules had a tendency to arrange in parallel (horizontally, in the case presented in Fig. 4b). This fraction for 'Xenia' included as well domains oriented at angle approximately similar to the mutual orientation of molecules for 'Conference' in Fig. 4a. This showed that a self-assembly mechanism of DASP molecules existed for both cultivars.

Figure 5 illustrates examples of a $1 \mathrm{M} \mathrm{KOH}$-extracted fraction, which is believed to be abundant in hemicellulose molecules. Molecules absorbed on mica had a rod-like shape of length within the range of $20-400 \mathrm{~nm}$ for 'Conference' and $80-400 \mathrm{~nm}$ for 'Xenia'. For 'Xenia' (Fig. 5b), the molecules were more curved, moreover they often formed tangled
Fig. 1 The method for determination of the height profile of chain-like molecules from AFM height image. The red line indicates the height profile, which was determined from the skeleton after segmentation with a minima threshold of $200 \mathrm{pm}$

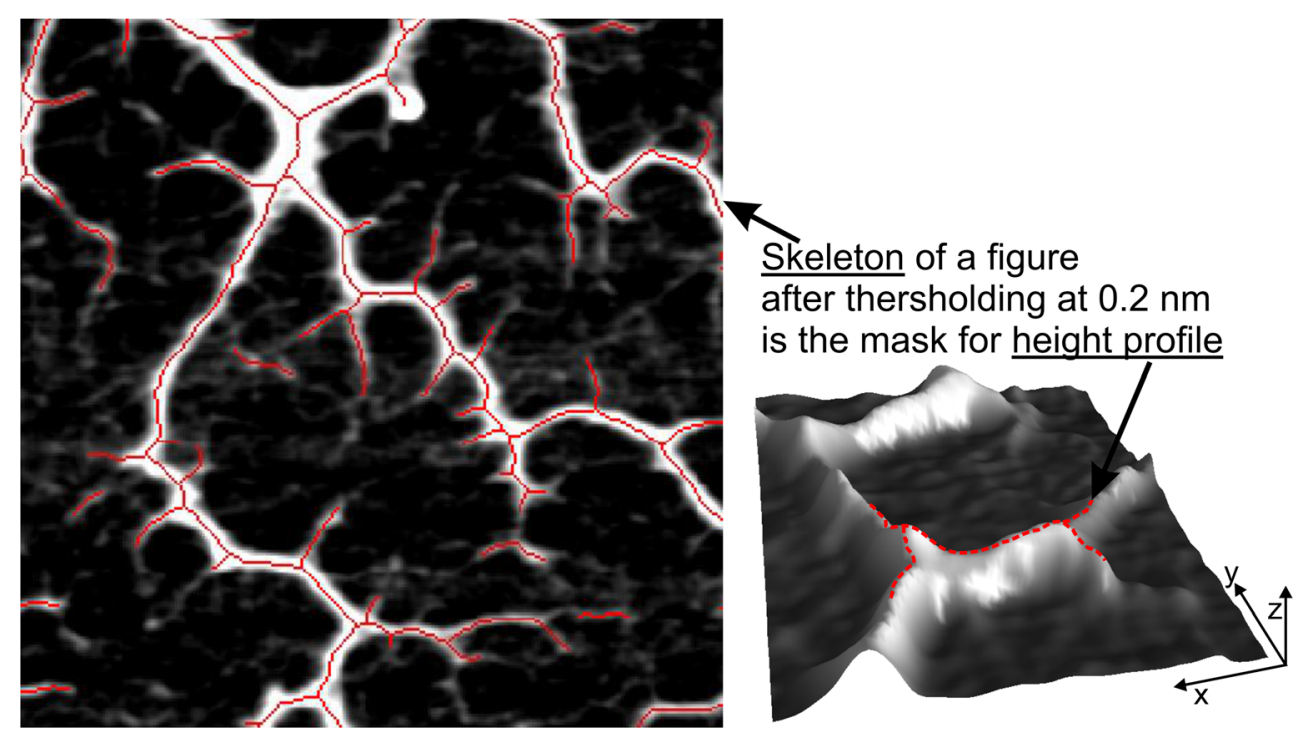



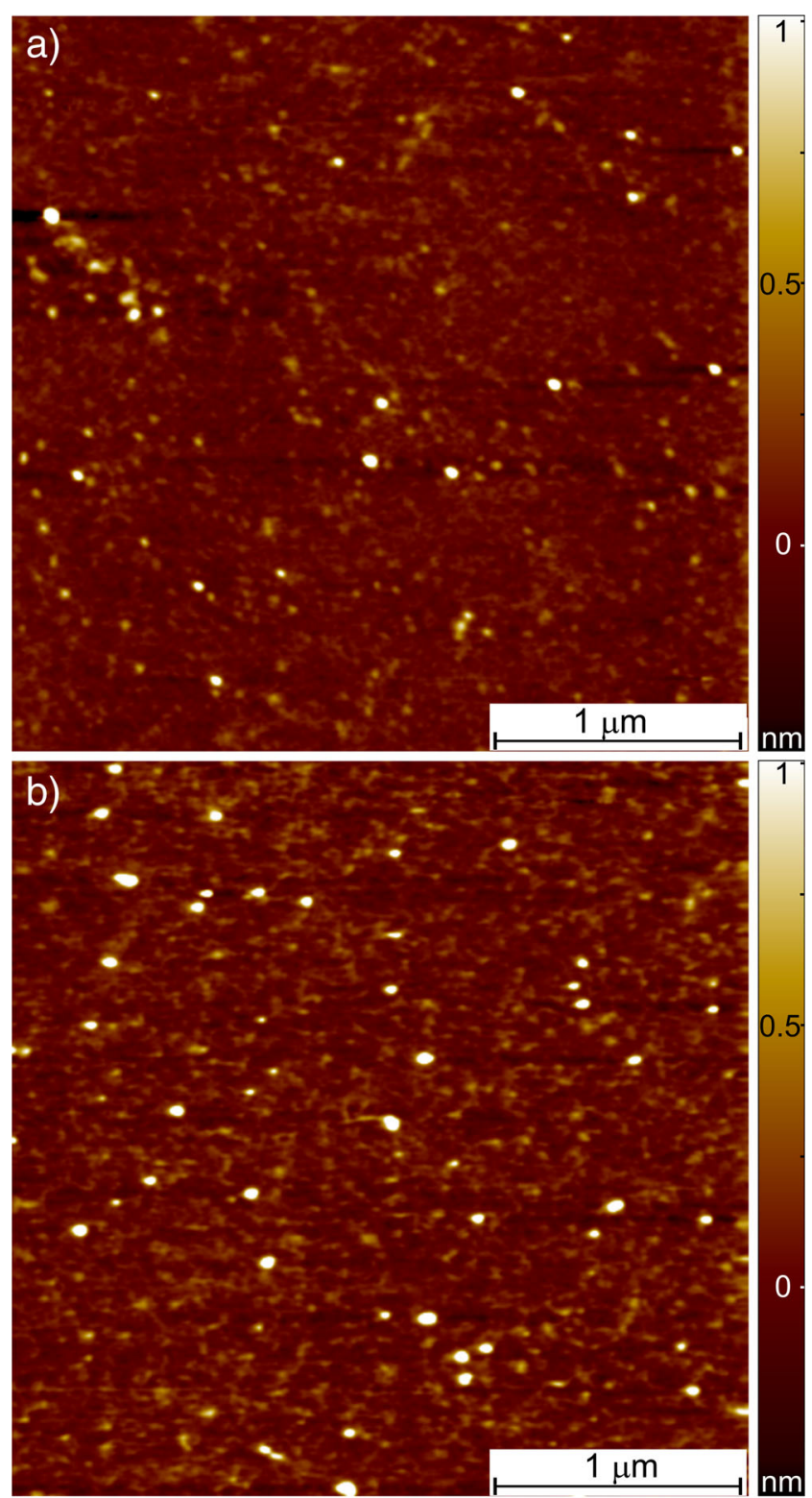

c)

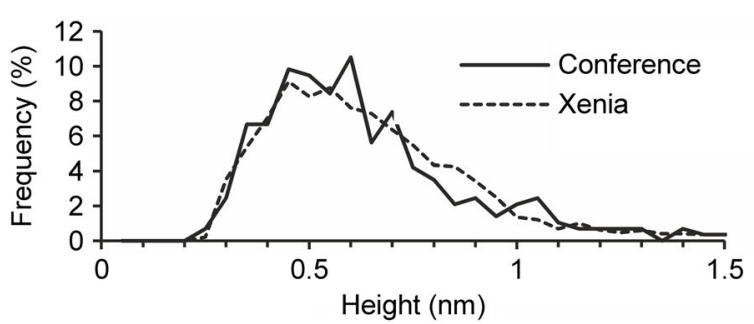

d)

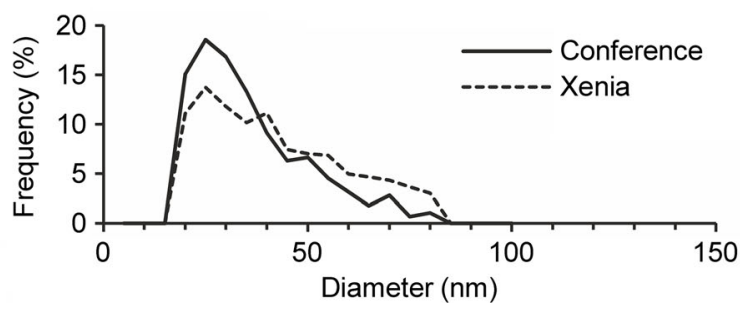

Fig. 2 Representative AFM height image of water-soluble pectins $(W S P$ ) on mica: a pear cv. 'Conference', b Pear cv. 'Xenia', c height distribution of WSP molecules, $\mathbf{d}$ diameter distribution of WSP molecules

assemblies (Fig. 5c). The structure of $1 \mathrm{M} \mathrm{KOH}$-extracted polysaccharides from this experiment was very different than those obtained by Chen et al. (2009) as a result of extraction with $\mathrm{NaOH} / \mathrm{NaBH}_{4}$ from Chinese cherries. In that case, hemicellulose appeared on AFM images as long, straight and linked branches. The height distribution of molecules presented in Fig. 5d for the two pear cultivars shows a substantial contribution of molecules, with a height of about 1 and $4 \mathrm{~nm}$ for 'Conference', whereas hemicellulose in 'Xenia' had only a very homogeneous diameter of about $1 \mathrm{~nm}$. These values are in agreement with heights of hemicellulose from Chinese cherries (Chen et al. 2009).

Figure 6 shows examples of AFM error images for cellulose assemblies in the cell walls of the two studied cultivars. In both cultivars, the assembly was rather random (example shown in Fig. 6b); however, parallel alignment of fibrils could often be noticed (example shown in Fig. 6a). Analysis of AFM error images did not reveal differences regarding diameter of the macrofibrils between the studied cultivars. Mean macrofibril diameter was $23 \pm 5 \mathrm{~nm}$ (range $12-55 \mathrm{~nm}, N=$ 1,260 ) and $23 \pm 6 \mathrm{~nm}$ (range 10-63 nm, $N=1,600$ ) for 'Conference' and 'Xenia', respectively. These diameters are very close to those previously measured by Cybulska et al. (2013) using a similar method on AFM height images for apples, which was in a range of $25 \mathrm{~nm}$ for most cultivars with the exception of the very crispy 'Honeycrisp', which had fibrils of about $37 \mathrm{~nm}$ in diameter.

Relationship Between the Nanostructure of Polysaccharides in the Cell Wall with the Texture of Pears

The textural properties for pears studied in this experiment are presented in Table 1. Statistically significant differences $(p<0.05)$ between cultivars were found in the case of instrumental variables (total AE events, firmness) and two sensory attributes (crispness and overall texture). These parameters were greater for 'Xenia'; moreover, hardness and juiciness were also higher for this cultivar, but not significantly so. These parameters show overall better quality and higher consumer acceptability of the 'Xenia' cultivar compared to 'Conference'.

In a simplified model, the mechanical properties of plant tissue depended on turgor, cell geometrical properties, cell wall properties and cell-to-cell bonding by middle lamella. This experiment considered cell wall polysaccharides, i.e., molecules that are abundant in both the cell wall and middle lamella, since the latter is mainly made of HG (Jarvis et al. 2003). 

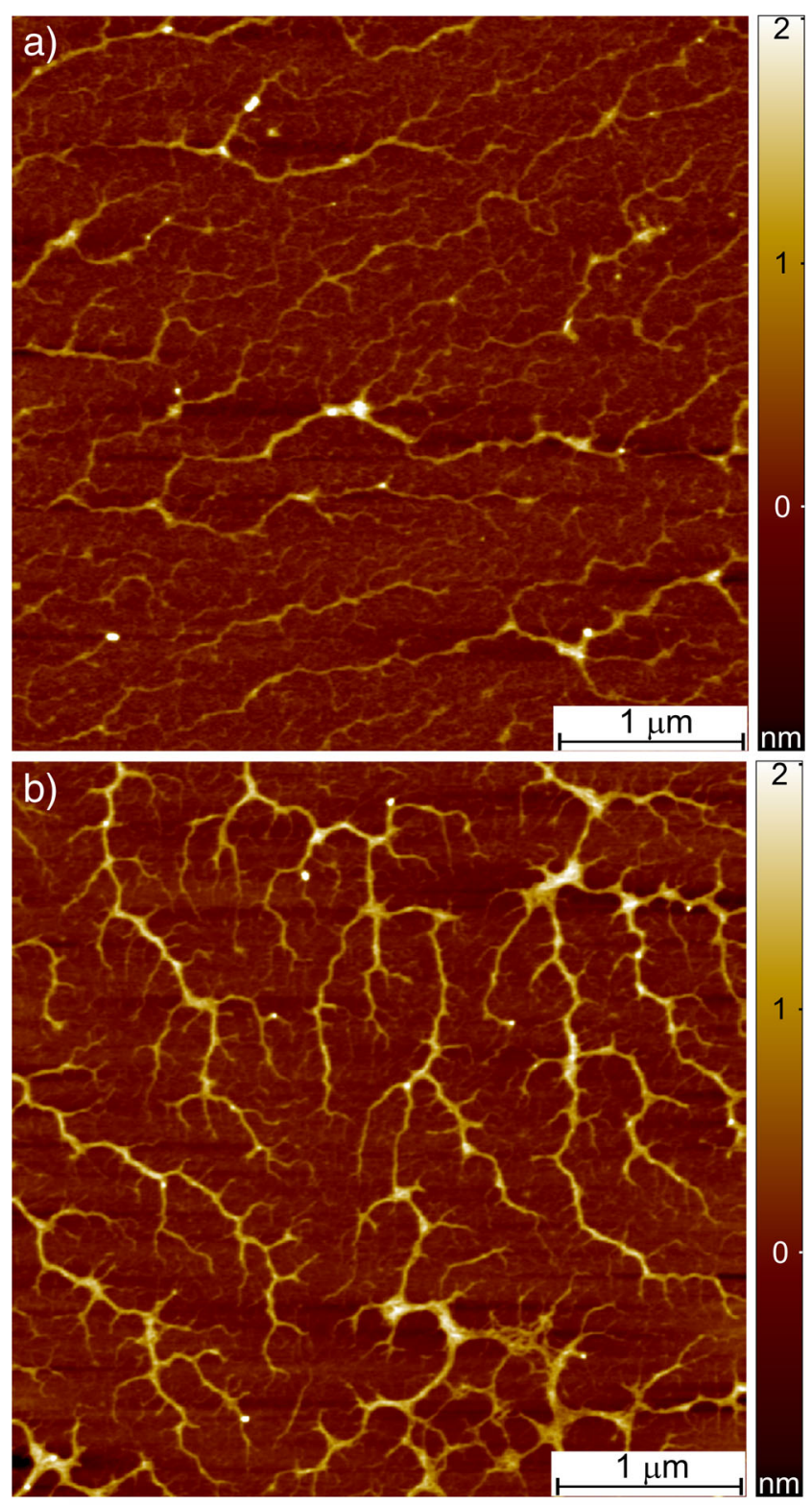

c)

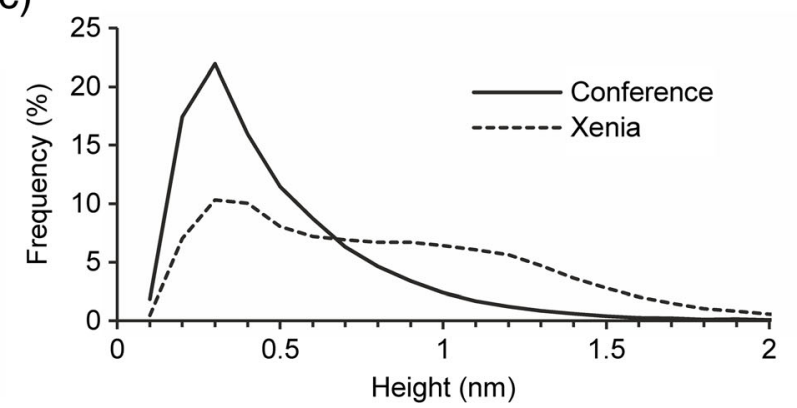

Fig. 3 Representative AFM height image of chelator soluble pectins $(C S P)$ on mica: a pear cv. 'Conference', b pear cv. 'Xenia', $\mathbf{c}$ height distribution of CSP molecules

An AFM study of each polysaccharide showed some distinct structural features between the two pear cultivars. To summarize, the 'Xenia' cultivar possessed slightly larger
Table 1 Branching index, texture properties, galacturonic acid content, calcium content and enzymatic activity (polygalacturonase and pectinmethylesterase) of 'Conference' and 'Xenia' pears used in experiment

\begin{tabular}{llll}
\hline Cultivar & & 'Conference' & 'Xenia' \\
\hline Branching index $\left(\mu \mathrm{m}^{-1}\right)$ & CSP & 5.6 & 6.2 \\
& DASP & 8.2 & Not detectable \\
Total acoustic emission events* & 31,622 & 75,218 \\
& & $(11,724)$ & $(6,540)$ \\
Firmness $(N)^{*}$ & & $76.4(6.0)$ & $86.8(4.8)$ \\
Crispness* & $60.5(20.8)$ & $85.0(7.0)$ \\
Hardness & & $58.5(16.4)$ & $68.0(10.7)$ \\
Juiciness & & $247.0(21.3)$ & $50.8(16.3)$ \\
Mealiness & & $48.4(17.8)$ & $16.6(15.0)$ \\
Overall texture* & & $68.0(13.5)$ \\
GalA content $(\mathrm{mg} / \mathrm{g}$ of AIR) & WSP & $56.76(1.41)$ & $20.17(0.18)$ \\
& CSP & $18.11(0.85)$ & $16.64(0.23)$ \\
& DASP & $93.25(0.88)$ & $81.44(1.38)$ \\
& insoluble & $10.50(0.21)$ & $9.38(0.13)$ \\
Calcium content $(\mathrm{mg} / \mathrm{g}$ of AIR) & $6.90(0.10)$ & $6.06(0.30)$ \\
PG activity $(\mu \mathrm{g}$ GalA/g of FM $\times 1 \mathrm{~min})$ & $8.96(1.10)$ & $30.99(1.13)$ \\
PME activity $(\mu \mathrm{mol} \mathrm{NaOH} / \mathrm{g}$ of FM $\times$ & $4.15(0.24)$ & $3.34(0.34)$ \\
1 min) & & & \\
\hline
\end{tabular}

Standard deviations are shown in parentheses

$W S P$ water soluble pectins, $C S P$ chelator (CDTA) soluble pectins, $D A S P$ diluted alkali $\left(\mathrm{Na}_{2} \mathrm{CO}_{3}\right)$ soluble pectins, $A I R$ alcohol insoluble residue, GalA galacturonic acid, $P G$ polygalacturonase, $P M E$ pectinmethylesterase, $F M$ fresh mass

*Significant difference at $p=0.05$ (Student $t$-test, $N=10$ ) between cultivars

WSP polymers, thicker and more branched chain-like CSP molecules, greater ability to create a dense network of DASP molecules and thinner but more homogeneous distribution of hemicellulose molecules with a tendency towards tangling. Only cellulose macrofibrils for both cultivars were very similar.

Water-soluble fraction (WSP) is believed to contain loosely linked and depolymerized pectins in cell walls. The height of objects on AFM images (Fig. 2b) of about $0.5 \mathrm{~nm}$ agrees roughly with the dimensions of a GalA unit, of which the theoretical diameter, calculated using the DFT method, was about $0.4-0.6 \mathrm{~nm}$. In particular, WSP was more abundant in the cell walls of 'Conference', as indicated by GalA content in Table 1 (5.7\% of AIR). The low PG activity for this cultivar suggests that further depolymerization of $\mathrm{HG}$ has been inhibited. For 'Xenia', the WSP fraction was much less abundant ( $2 \%$ of AIR), although substantially higher PG activity at this stage of maturity was noted. AFM analysis also showed slightly larger molecules of WSP for 'Xenia', which could be explained by a lower 

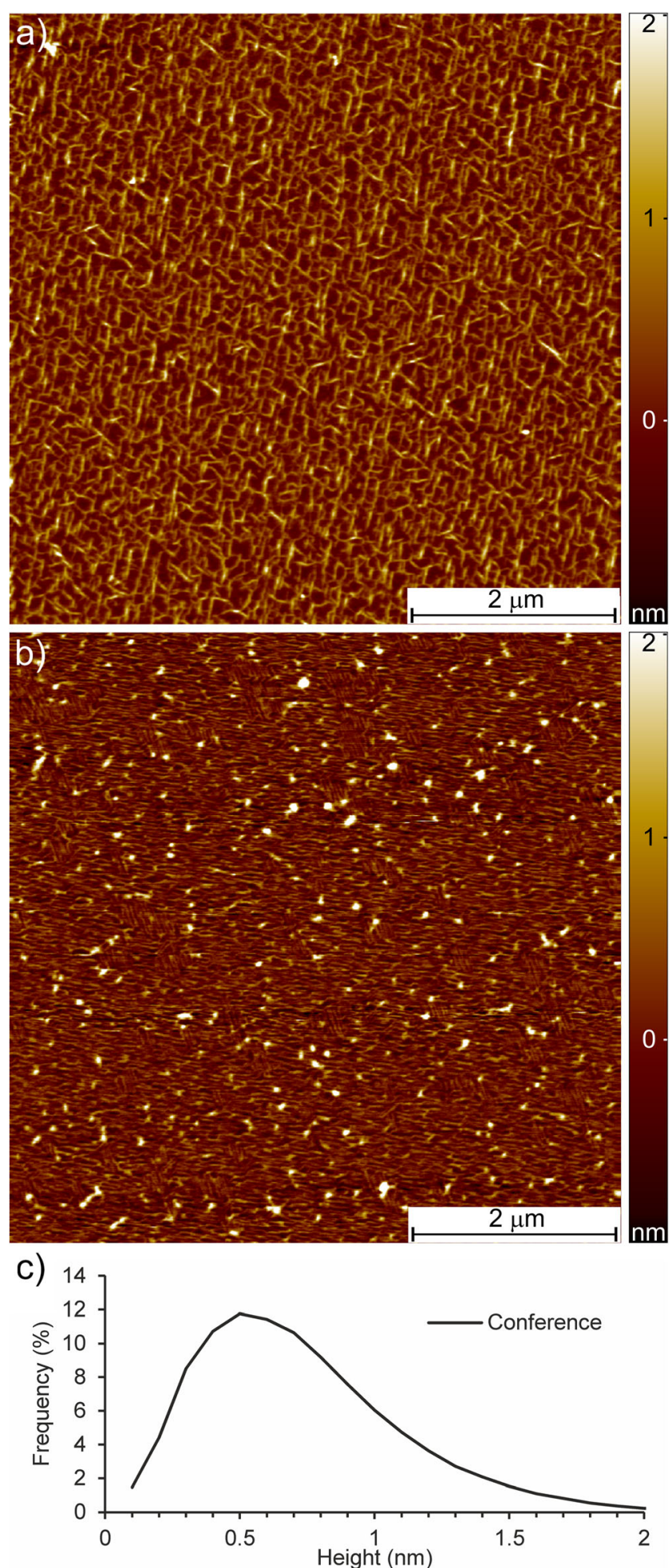

Fig. 4 AFM height images of diluted alkali soluble pectins $(D A S P)$ on mica: a pear cv. 'Conference', b pear cv. 'Xenia', c height distribution of DASP molecules for 'Conference'

degree of current depolymerization. This may be related to the higher firmness of 'Xenia' pears.

Pectin methylesterase (PME) activity as well as GalA content in the CSP fraction and calcium content were at
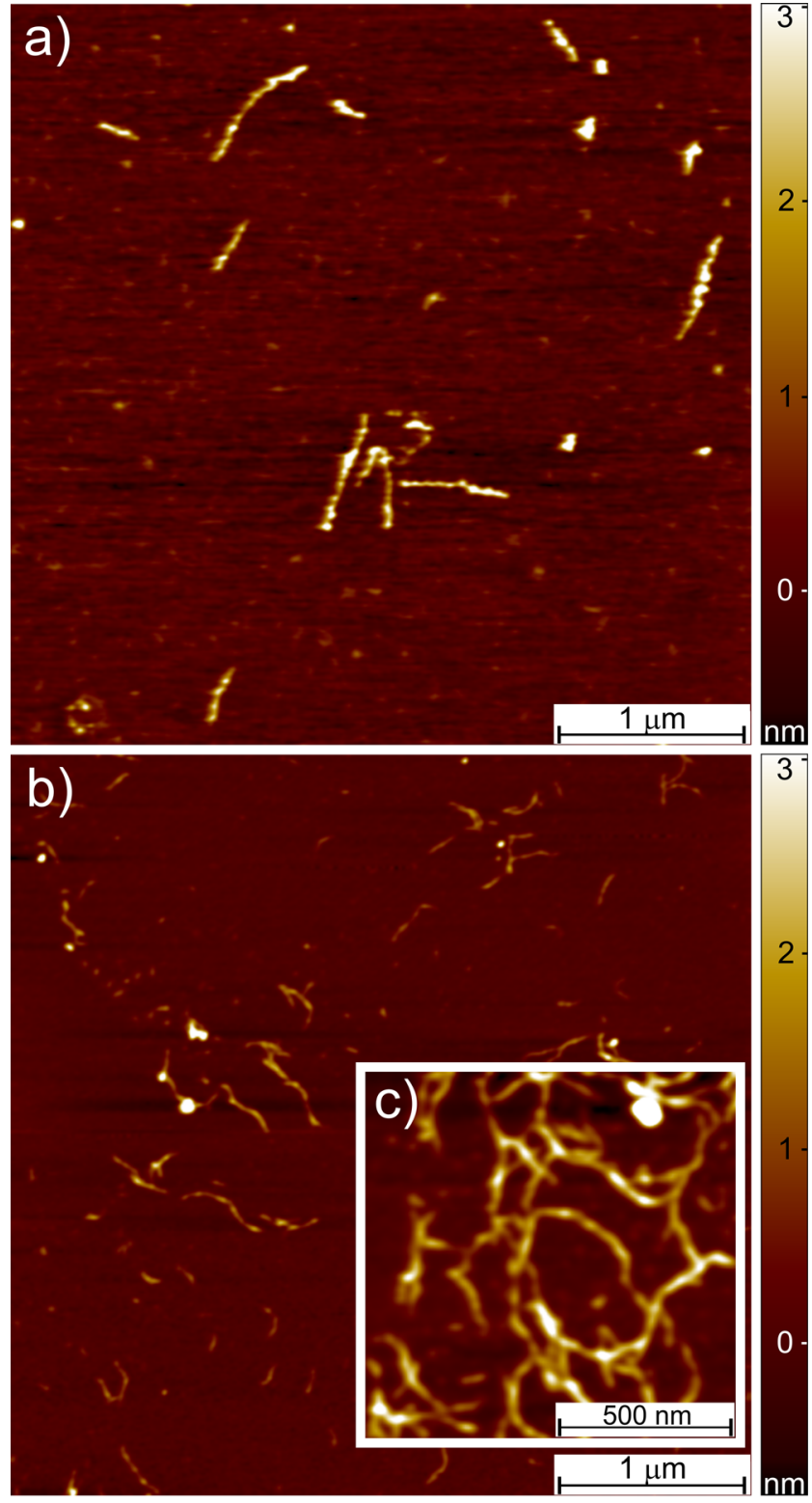

d)

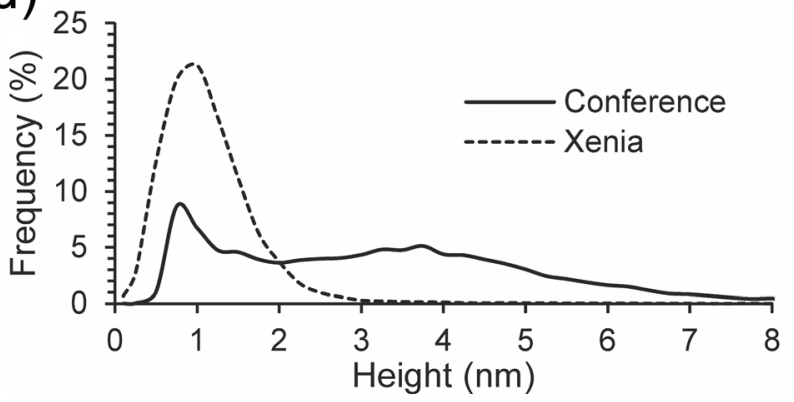

Fig. 5 AFM height images of $1 \mathrm{M} \mathrm{KOH}$ fraction (hemicellulose) on mica: a pear cv. 'Conference', b pear cv. 'Xenia', c $1 \times 1 \mu \mathrm{m}$ scan of tangled molecules in 'Xenia' cell walls, $\mathbf{d}$ height distribution of molecules in $1 \mathrm{M} \mathrm{KOH}$ fraction

similar levels for both cultivars (Table 1). PME caused deesterification of HG backbone and promoted in this way 

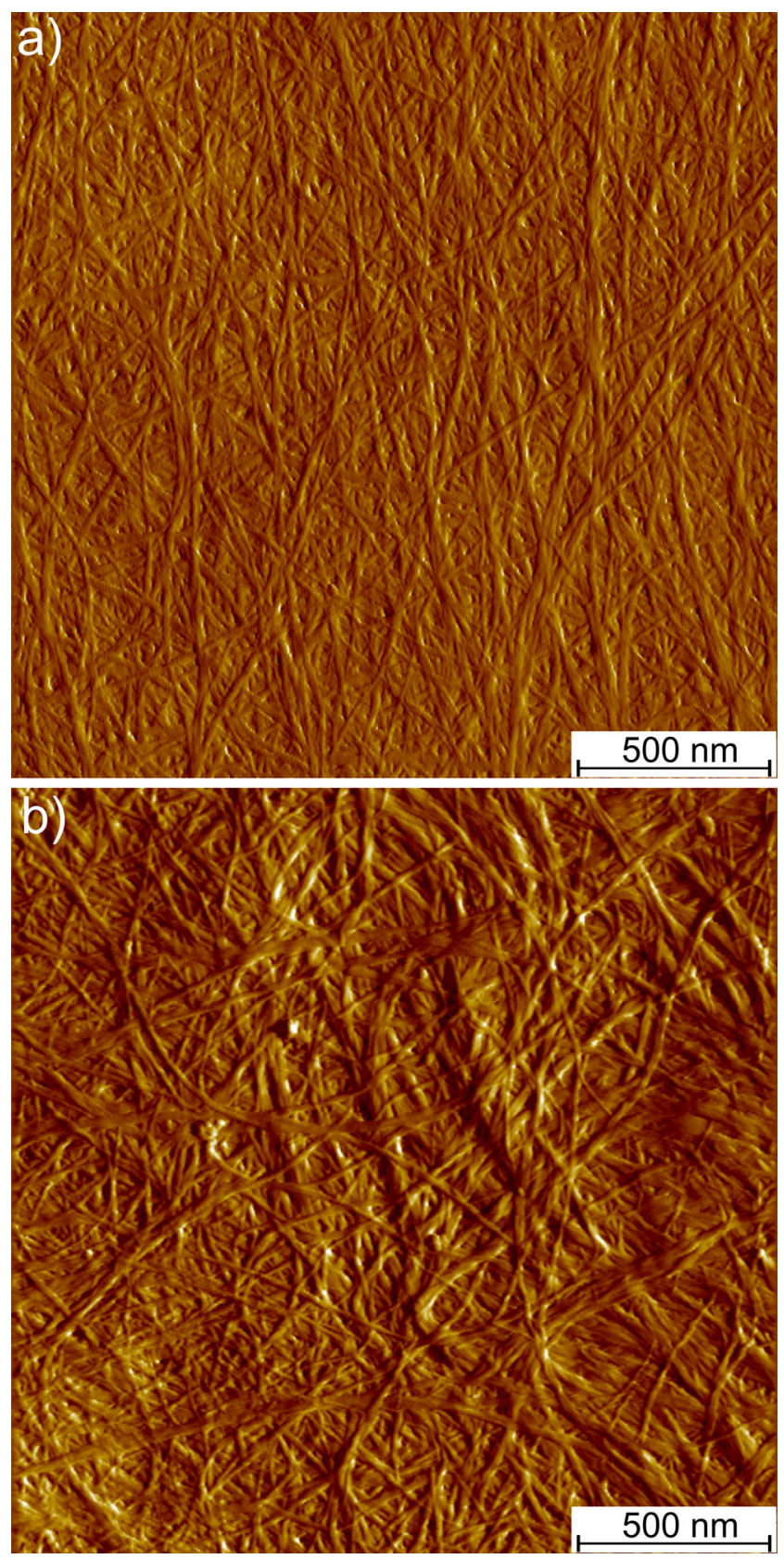

Fig. 6 AFM error images of cellulose: a pear cv. 'Conference', $\mathbf{b}$ pear cv. 'Xenia'

cross-linking by calcium ions. This mechanism, which occurs mainly in the middle lamella, substantially affects the firmness of fruits. A similar content of these constituents for both cultivars suggests that the amount of junction zones created by calcium ions would also be approximate. CDTA used for extraction cleaves calcium bridges between the smooth regions. Therefore, CSP pectins are believed to be enriched in partially esterified HG, mostly from the middle lamella (Redgwell et al. 1992; Willats et al. 2006) and with a low content of neutral sugars. However, AFM study typically shows branched structures, as in the current experiment for pears, which may be covalently linked HG with RG-1 (Kirby et al. 2008; Round et al. 2010, 2001; Pose et al. 2012; Coenen et al. 2007). The AFM study showed that the 'Xenia' cultivar possessed thicker CSP molecules that were also more branched than in 'Conference'. 'Conference' had more homogeneous thickness distribution with a peak within a subnanometre range, which agrees with the theoretical diameter of the HG backbone. For 'Xenia', a substantial extension of thickness toward $1.3 \mathrm{~nm}$ was noted, which - taking into account more branched structure - may suggest an existence of neutral sugars linked as the side branches to HG backbone. A more branched structure, despite a similar amount of calcium bridges, has the consequence of stronger cell-to-cell adhesion and therefore greater texture of fruit in 'Xenia', in particular, lowering its mealiness.

$\mathrm{Na}_{2} \mathrm{CO}_{3}$-extracted pectins from pears (DASP) had ability to create a network on mica. Moreover, for 'Xenia' a stronger tendency to dense packing of linear polymers was observed (Fig. 4). The measured diameter of these pectins for 'Conference' was within the range of $0.3-1 \mathrm{~nm}$. A space among DASP molecules, in the case of 'Conference' pears, of several dozen nanometres was sufficient for accommodating cellulose-hemicellulose fibrils. Thus, the pectin network may play an important role in the mechanics of cell walls. The two pear cultivar examples show that this fraction may contribute to higher firmness and better texture in the 'Xenia' cultivar due to densely packed DASP molecules.

A $1 \mathrm{M} \mathrm{KOH}$-extracted fraction is believed to be rich in hemicellulose. The role of hemicellulose in cell wall mechanics is to cross-link cellulose fibrils. A length of hemicellulose molecules from pears $(20-400 \mathrm{~nm}$ ) was sufficient to fulfil this role. The measured diameter of molecules in this fraction was slightly greater than in pectins, which obviously arose from different backbone and the presence of side-sugars in hemicellulose. The side-sugars are likely responsible for the substantial thickening of hemicelluloses in 'Conference' pears. In 'Xenia', hemicellulose was more curved, thinner and displayed a tendency towards tangling. Cellulose may be cross-linked with hemicellulose via hydrogen bonds when conformation of hemicellulose is favourable (Albersheim et al. 2011). Based on AFM images, it can thus be suggested that hemicellulose in 'Xenia', due to thinner and more flexible chains, more favourably cross-links cellulose in cell walls, contributing in this way to an increase in cell wall stiffness.

Previous studies (Cybulska et al. 2013) showed that cellulose thickness correlates positively with the firmness and texture of apple fruit. In this study, we did not find significant differences between the cellulose diameter of two studied pear cultivars; therefore, differences in textural properties were not related to this nanostructural parameter. 


\section{Conclusions}

This study concerned the structure of individual polysaccharides abundant in the cell walls of pears of distinct texture and firmness. The design of this experiment focused on various cell wall building blocks from the same material, which allowed for some elucidation on the role of nanostructure in the macroscopic texture and firmness of pear fruit.

Nanostructure evaluation with AFM, combined with image analysis, showed that macroscopic texture of pears relates to the nanostructural features of polysaccharides in cell walls, particularly pectins and hemicellulose. Less degraded, thicker and more branched pectin molecules are associated with better firmness and more favourable texture. Hemicellulose provides a positive contribution to texture when they are thinner and more flexible, which may make cellulose cross-linking possible. The role of cellulose diameter has not yet been confirmed, due to the similar structure of macrofibrils in the cell walls of both cultivars.

Results of this experiment provide insight into fundaments of fruit texture at certain scale length. This knowledge is indispensable in multi-scale experiments and modelling which also includes cell wall thickness, cells size and turgor - for fully explaining an actual macroscopic texture.

Acknowledgments This work was supported by the project DEC2011/01/B/NZ9/00787 of the National Science Centre, Poland.

Open Access This article is distributed under the terms of the Creative Commons Attribution License which permits any use, distribution, and reproduction in any medium, provided the original author(s) and the source are credited.

\section{References}

Aguilera, J. M. (2005). Why food microstructure? Journal of Food Engineering, 67, 3-11.

Albersheim, P., Alan Darvill, A., Roberts, K., Sederoff, R., Staehelin, A. (2011). Plant cell walls. Gerland Sciences, Taylor \& Francis Group.

Blumenkrantz, N., \& Asboe-Hansen, G. (1973). New method for quantitative determination of uronic acid. Analytical Biochemistry, 54, 484-489.

Bourne, M. C. (2002). Food texture and viscosity: concept and measurement (2nd ed.). London: Academic Press.

Brummell, D. A., \& Harpster, M. H. (2001). Cell wall metabolism in fruit softening and quality and its manipulation in transgenic plants. Plant Molecular Biology, 47, 311-340.

Burton, R. A., Gidley, M. J., \& Fincher, G. B. (2010). Heterogeneity in the chemistry, structure and function of plant cell walls. Nature Chemical Biology, 6, 724-732.

Chen, F., Zhang, L., An, H., Yang, H., Sun, X., Liu, H., Yao, Y., \& Li, L. (2009). The nanostructure of hemicellulose of crisp and soft Chinese cherry (Prunus pseudocerasus L.) cultivars at different stages of ripeness. LWT: Food Science and Technology, 42, 125-130.

Coenen, G. J., Bakx, E. J., Verhoef, R. P., Schols, H. A., \& Voragen, A. (2007). Identification of the connecting linkage between homo- or xylogalacturonan and rhamnogalacturonan type I. Carbohydrate Polymers, 70, 224-235.

Cybulska, J., Konstankiewicz, K., Zdunek, A., \& Skrzypiec, K. (2010a). Nanostructure of natural and model cell wall materials. International Agrophysics, 24, 107-114.

Cybulska, J., Pieczywek, P. M., \& Zdunek, A. (2012). The effect of $\mathrm{Ca}^{2+}$ and cellular structure on apple firmness and acoustic emission. European Food Research and Technology, 235, 119-128.

Cybulska, J., Vanstreels, E., Ho, Q. T., Courtin, C. M., Van Craeyveld, V., Nicolaï, B., Zdunek, A., \& Konstankiewicz, K. (2010b). Mechanical characteristics of artificial cell walls. Journal of Food Engineering, 96, 287-294.

Cybulska, J., Zdunek, A., \& Konstankiewicz, K. (2011). Calcium effect on mechanical properties of model cell walls and apple tissue. Journal of Food Engineering, 102, 217-223.

Cybulska, J., Zdunek, A., Psonka-Antonczyk, K. M., \& Støkke, B. T. (2013). The relation of apple texture with cell wall nanostructure studied using an atomic force microscope. Carbohydrate Polymers, $92,128-137$

Dubois, M. K., Gilles, A., Hamilton, J. K., Rebers, P. A., \& Smith, F. (1956). Colorimetric method for determination of sugars and related substances. Analytical Chemistry, 28(3), 350-356.

Eichhorn, S. J., Dufresne, A., Aranguren, M., Marcovich, N. E., Capadona, J. R., Rowan, S. J., Weder, C., Thielemans, W., Roman, M., Renneckar, S., Gindl, W., Veigel, S., Keckes, J., Yano, H., Abe, K., Nogi, M., Nakagaito, A. N., Mangalam, A., Simonsen, J., Benight, A. S., Bismarck, A., Berglund, L. A., \& Peijs, T. (2010). Review: current international research into cellulose nanofibres and nanocomposites. Journal of Materials Science, 45(1), 1-33.

Fanta, S. W., Vanderlinden, W., Abera, M. K., Verboven, P., Karki, R., Ho, Q. T., Feyter, S. D., Carmeliet, J., \& Nicolai, B. M. (2012). Water transport properties of artificial cell walls. Journal of Food Engineering, 108, 393-402.

Geitmann, A. (2010). Mechanical modeling and structural analysis of the primary plant cell wall. Current Opinion in Plant Biology, 13, 693 699.

Gibson, L. J. (2012). The hierarchical structure and mechanics of plant materials. Journal of the Royal Society Interface, 9, 2749-2766.

Iwamoto, S., Kai, W., Isogai, A., \& Iwata, T. (2009). Elastic modulus of single cellulose microfibrils from tunicate measured by atomic force microscopy. Biomacromolecules, 10(9), 2571-2576.

Jarvis, M. C. (2011). Plant cell walls: supramolecular assemblies. Food Hydrocolloids, 25, 257-262.

Jarvis, M. C., Briggs, S. P. H., \& Knox, J. P. (2003). Intercellular adhesion and cell separation in plants. Plant Cell \& Environment, 26, 977 989.

Kirby, A. R. (2011). Atomic force microscopy of plant cell walls. The plant cell wall. Methods in Molecular Biology, 715, 169-78.

Kirby, A. R., Gunning, A. P., Morris, V. J., \& Ridout, M. J. (1995a). Observation of the helical structure of the bacterial polysaccharide acetan by atomic force microscopy. Biophysical Journal, 68, 359-362.

Kirby, A. R., Gunning, A. P., \& Morris, V. J. (1995b). Imaging xanthan gum by atomic force microscopy. Carbohydrate Research, 267, $161-166$

Kirby, A. R., Gunning, A. P., Waldron, K. W., Morris, V. J., \& Ng, A. (1996). Visualization of plant cell walls by atomic force microscopy. Biophysical Journal, 70, 1138-1143.

Kirby, A. R., MacDougall, A. J., \& Morris, V. J. (2008). Atomic force microscopy of tomato and sugar beet pectin molecules. Carbohydrate Polymers, 71, 640-647.

Li, Z., Yang, H., Li, P., Liu, J., Wang, J., \& Xu, Y. (2013). Fruit biomechanics based on anatomy: a review. International Agrophysics, 27, 97-106.

Liu, H., Chen, F., Yang, H., Yao, Y., Gong, X., Xin, Y., \& Ding, C. (2009). Effect of calcium treatment on nanostructure of chelate- 
soluble pectin and physicochemical and textural properties of apricot fruits. Food Research International, 42, 1131-1140.

McCann, M. C., Wells, B., \& Roberts, K. (1990). Direct visualization of cross-links in the primary plant cell wall. Journal of Cell Science, 96, 323-334.

Mohnen, D. (2008). Pectin structure and biosynthesis. Current Opinion in Plant Biology, 11, 266-277.

Morris, V. J., Gromer, A., Kirby, A. R., Bongaerts, R. J. M., \& Gunning, A. P. (2011). Using AFM and force spectroscopy to determine pectin structure and (bio) functionality. Food Hydrocolloids, 25, 230-237.

Niklas, K. J. (1992). Plant biomechanics, an engineering approach to plant form and function. The University Chicago Press.

Pauly, M., Albersheim, P., Darvill, A., \& York, W. S. (1999). Molecular domains of the cellulose/xyloglucan network in the cell wall of higher plants. The Plant Journal, 20, 629-639.

Pose, S., Kirby, A. R., Mercado, J. A., Morris, V. J., \& Quesada, M. A. (2012). Structural characterization of cell wall pectin fractions in ripe strawberry fruits using AFM. Carbohydrate Polymers, 88, 882-890.

Redgwell, R. J., Melton, L. D., \& Brasch, D. J. (1988). Cell wall polysaccharides of kiwifruit (Actinidia deliciosa): chemical features in different tissue zones of the fruit at harvest. Carbohydrate Research, 182, 241-258.

Redgwell, R. J., Melton, L. D., \& Brasch, D. J. (1992). Cell wall dissolution in ripening kiwifruit (Actinidiadeliciosa): solubilization of the pectic polymers. Plant Physiology, 98, 71-81.

Ridley, B. L., O’Neill, M. A., \& Mohnen, D. (2001). Pectins: structure, biosynthesis, and oligogalacturonide-related signaling. Phytochemistry, 57, 929-967.

Round, A. N., Rigby, N. M., MacDougall, A. J., \& Morris, V. J. (2010). A new view of pectin structure revealed by acid hydrolysis and atomic force microscopy. Carbohydrate Research, 345, 487-497.

Round, A. N., Rigby, N. M., MacDougall, A. J., Ring, S. G., \& Morris, V. J. (2001). Investigating the nature of branching in pectin by atomic force microscopy and carbohydrate analysis. Carbohydrate Research, 331, 337-342.

Waldron, K. W., Smith, A. C., Parr, A. J., Ng, A., \& Parker, M. L. (1997). New approaches to understanding and controlling cell separation in relation to fruit and vegetable texture. Trends in Food Science \& Technology, 8, 213-221.

Wei, J., Ma, F., Shi, S., Qi, X., Zhu, X., \& Yuan, J. (2010). Changes and postharvest regulation of activity and gene expression of enzymes related to cell wall degradation in ripening apple fruit. Postharvest Biology and Technology, 56, 147-154.

Willats, W. G. T., Knox, J. P., \& Mikkelsen, J. D. (2006). Pectin: new insights into an old polymer are starting to gel. Trends in Food Science \& Technology, 17, 97-104.

Xin, Y., Chen, F., Yang, H., Zhang, P., Deng, Y., \& Yang, B. (2010). Morphology, profile and role of chelate-soluble pectin on tomato properties during ripening. Food Chemistry, 121, 372-380.

Yang, H., An, H., Feng, G., Li, Y., \& Lai, S. (2005). Atomic force microscopy of the water-soluble pectin of peaches during storage. European Food Research and Technology, 220, 587-591.

Yang, H., Chen, F., An, H., \& Lai, S. (2009). Comparative studies on nanostructures of three kinds of pectins in two peach cultivars using atomic force microscopy. Postharvest Biology and Technology, 51, 391-398.

Zdunek, A., \& Bednarczyk, J. (2006). Effect of mannitol treatment on ultrasound emission during texture profile analysis of potato and apple tissue. Journal of Texture Studies, 37, 339-359.

Zdunek, A., Cybulska, J., Konopacka, D., \& Rutkowski, K. (2010a). New contact acoustic emission detector for texture evaluation of apples. Journal of Food Engineering, 99, 83-91.

Zdunek, A., Cybulska, J., Konopacka, D., \& Rutkowski, K. (2011a). Evaluation of apple texture with contact acoustic emission detector: a study on performance of calibration models. Journal of Food Engineering, 106, 80-87.

Zdunek, A., Cybulska, J., Konopacka, D., \& Rutkowski, K. (2011b). Inter-laboratory analysis of sensory texture of stored apples. International Agrophysics, 25, 67-75.

Zdunek, A., Konopacka, D., \& Jesionkowska, K. (2010b). Crispness and crunchiness judgment of apples based on contact acoustic emission. Journal of Texture Studies, 41, 75-91.

Zdunek, A., \& Umeda, M. (2005). Influence of cell size and cell wall volume fraction on failure properties of potato and carrot tissue. Journal of the Texture Studies, 36, 25-43.

Zhang, L., Chen, F., Yang, H., Sun, X., Liu, H., Gong, X., Jiang, C., \& Ding, C. (2010). Changes in firmness, pectin content and nanostructure of two crisp peach cultivars after storage. LWT: Food Science and Technology, 43, 26-32.

Zhang, L., Chen, F., Yang, H., Ye, X., Sun, X., Liu, D., Yang, B., An, H., \& Deng, Y. (2012). Effects of temperature and cultivar on nanostructural changes of water-soluble pectin and chelate-soluble pectin in peaches. Carbohydrate Polymers, 87, 816-821. 